\title{
c-KIT gene mutation and clonal origin of multiple gastrointestinal stromal tumors occurring in the peritoneum
}

\author{
LI GONG $^{1 *}$, YAN-HONG LI ${ }^{1,2^{*}}$, JUN WANG $^{1}$, XIAO-YAN LIU ${ }^{1}$ and WEI ZHANG ${ }^{1}$ \\ Departments of ${ }^{1}$ Pathology, and ${ }^{2}$ Gynaecology and Obstetrics, Tangdu Hospital, \\ Fourth Military Medical University, Xi'an 710038, Shaanxi, P.R. China
}

Received December 22, 2008; Accepted July 13, 2009

DOI: $10.3892 / \mathrm{mmr} \_00000205$

\begin{abstract}
The present study investigated multiple extragastrointestinal stromal tumors (EGISTs) occurring in the peritoneum, identified their clinicopathologic and immunohistochemical features, and examined their c-KIT gene mutations, clonal status and clonal relationships. Fifteen different tumors of a multiple EGIST from the same female patient were examined by microscopy and immunohistochemistry, then genomic DNA was isolated from the lesions and, as the control, the surrounding fibrous connective tissues. PCR amplification and sequencing were used to investigate the mutation status of c-KIT gene exons 9, 11, 13 and 17. Finally, a clonality assay was conducted based on X-chromosome inactivation mosaicism in female somatic tissues and polymorphisms of the phosphoglycerate kinase and androgen receptor genes. Immunohistochemical analysis revealed CD117- and CD34positive reactivity in the tumors. Mutation analysis identified the c-KIT gene mutation in exon 13. The clonality assay revealed a loss of $\mathrm{X}$-chromosome inactivation mosaicism and an identical inactivated allele in all 15 nodules. No similar findings were observed in the surrounding fibrous connective tissues. The c-KIT gene mutation was found in the multiple EGISTs from the patient. The EGIST, like most tumors, was of monoclonal origin. This and the identical inactivated allele found in the nodules indicated a common clonal origin for the tumor.
\end{abstract}

\section{Introduction}

Gastrointestinal stromal tumors (GISTs) are the most common mesenchymal tumors of the gastrointestinal tract. It is now

Correspondence to: Professor Wei Zhang, Department of Pathology, Tangdu Hospital, Fourth Military Medical University, Xi'an 710038, Shaanxi, P.R. China

E-mail: glzwd16@fmmu.edu.cn

${ }^{*}$ Contributed equally

Key words: multiple extragastrointestinal stromal tumors, monoclonality, c-KIT gene mutation known that their cells of origin are the interstitial cells of Cajal. The commonality of these tumors is immunohistochemical staining positive for CD117, also known as c-KIT, which is located at 4q11-12. Several studies have revealed various c-KIT oncogene mutations, including exon 11 encoding the juxtamembrane domain, exon 9 encoding the extra-cellular domain, and exons 13 and 17 encoding the tyrosine kinase domain (1).

GISTs can occur in the muscularis mucosa and muscularis propria layers from the esophagus to the rectum, and in extragastrointestinal locations such as the mesentery, omentum and peritoneum (2-4). Their most common anatomic sites of origin are the stomach (60-70\%), small intestine (20-30\%), colon and rectum (5\%), and abdominal cavity (5-7). Omentum, mesentery and retroperitoneal tumors constitute less than $5 \%$ of GISTs $(3,8,9)$.

Malignant GISTs generally metastasize to the omentum and the mesentery. However, primary tumors may develop in the omentum, mesentery and peritoneum. Extragastrointestinal stromal tumors (EGISTs) of the peritoneum are rare, and multiple malignant EGISTs of the peritoneum have not been reported in recent studies. Moreover, only a few cases involving the clonality of multiple GISTs have been reported in the literature $(10,11)$. Here, we describe a case of multiple and malignant EGISTs in the peritoneum, and elucidate their immunohistochemical and clinicopathologic characteristics. The clonality and relationships between these tumors were additionally investigated to confirm their neoplastic nature.

\section{Materials and methods}

Case presentation. A 34-year-old female patient who had been experiencing periodic abdominal pain for seven days was admitted to the Department of General Surgery, Tangdu Hospital (Fourth Military Medical University, Xi'an, ShaanXi, P.R. China). During physical examination, two masses of $10 \mathrm{~cm}$ and $7 \mathrm{~cm}$ in diameter were identified in the left upper and left lower quadrant of the abdomen, respectively. Abdominal ultrasonography and computed tomography (CT) revealed multiple round and well-defined soft-tissue masses with homogenous and heterogeneous patterns in the uterus and spleen, between the uterus and bladder, in the right lobe of the liver and in the parietal peritoneum. The CT did not reveal liver metastases and lymph nodes of pathological size. Laboratory tests were normal, including levels of AFP $<10 \mu \mathrm{g} / 1, \mathrm{CEA}<7.0 \mu \mathrm{g} / \mathrm{l}$, and 
CA125 $<10 \mu \mathrm{g} / \mathrm{l}$. Tumors with peritoneal and mesenteric invasion were resected by surgery, and biopsies were performed. Written informed consent was obtained from the patient.

Immunohistochemistry. Immunostaining was performed using a streptavidin-labeled peroxidase (S-P) Kit (KIT9730) according to the manufacturer's instructions. Primary antibodies included mouse anti-human monoclonal antibodies (mAb) to CD34, desmin, nerve specificity enolase (NSE), nerve fiber (NF) and glial fibrillary acidic protein (GFAP), rabbit anti-human polyclonal antibodies to CD117, S-100 protein, smooth muscle actin (SM-actin), cytokeratin (CK), epithelial membrane antigen (EMA), mesothelial cells (MCs), $\mathrm{CR}$ and HMB45, as well as vimentin for mouse anti-pig mAb. All reagents were supplied by Maxim Biotechnology Corp. Ltd. (Fuzhou, P.R. China).

Microdissection and DNA extraction. Eight $10-\mu \mathrm{m}$ tissue sections from the 15 tumor nodules were placed on a UV-absorbing membrane and used for laser microdissection by LMD6000 (Leica Microsystems Ltd., Wetzlar, Germany). After H\&E staining, the slides were mounted on a microstat, then the selected lesion was dissected using a UV laser beam with motorized optical beam scanning. The dissectate (with the attached specimen) fell into the cap of the selected $0.5 \mathrm{ml}$ microcentrifuge tube. Lysate buffer $(40 \mu \mathrm{l})$ and $10 \mu \mathrm{l}$ of proteinase $\mathrm{K}$ were added to the cap. For each dissected lesion, surrounding fibrous connective tissue was isolated and analyzed as the control. The microcentrifuge tubes were placed in a $48^{\circ} \mathrm{C}$ waterbath for digestion. After $12-20 \mathrm{~h}$ of digestion, the genomic DNA was examined by $2 \%$ agarose electrophoresis and stored at $-20^{\circ} \mathrm{C}$.

PCR amplification for clonality assay. Nested polymerase chain reaction (PCR) was used for the amplification and detection of single nucleotide polymorphism (SNP) sites in the PGK gene, and for the determination of the length of the CAG short-tandem repeat polymorphism in exon 1 of the AR gene. In brief, two pairs of primers were used to amplify the PGK gene: PGK1A, 5'-CTG TTC CTG CCC GCG CGG TGT TCC GCA TTC-3'; PGK1B, 5'-ACG CCT GTT ACG TAA GCT CTG CAG GCC TCC-3'; PGK2A, 5'-AGC TGG ACG TTA AAG GGA AGC GGG TCG TTA-3'; and PGK2B, 5'-TAC TCC TGA AGT TAA ATC AAC ATC CTC TTG-3'. Genomic DNA $(10 \mu \mathrm{l})$ extracted from the lesion and non-lesion tissue, respectively, was incubated with 5 Units of $\mathrm{HpaII}$ (Promega, Madison, WI, USA) at $37^{\circ} \mathrm{C}$ for $3 \mathrm{~h}$ in a $20-\mu \mathrm{l}$ volume containing $0.2 \mu \mathrm{l}$ of $10 \mathrm{~g} / \mathrm{l}$ bovine serum albumin (BSA) and $2 \mu \mathrm{l}$ of $10 \mathrm{X}$ reaction buffer. The digested DNA samples (5 $\mu \mathrm{l}$ each) were subjected to nested PCR. The 50- $\mu 1$ reaction mixture contained $4 \mu \mathrm{l}$ of $10 \mathrm{mM}$ dNTP (Gibco Brl., Life Technologies Inc., Gaithersburg, MD, USA), the PGK1A and PGK1B primers (0.4 pmol each), $5 \mu \mathrm{l}$ of $10 \mathrm{X}$ buffer, $1.5 \mu \mathrm{l}$ of $50 \mathrm{mM} \mathrm{MgCl}_{2}$, and 2.5 Units of Taq DNA polymerase (Gibco). Amplification was conducted using a PT-200 thermocycler (MJ Research, Inc., Watertown, MA, USA) for 35 cycles $\left(94^{\circ} \mathrm{C}\right.$ for $40 \mathrm{sec}$, $58^{\circ} \mathrm{C}$ for $50 \mathrm{sec}$ and $72^{\circ} \mathrm{C}$ for $\left.1 \mathrm{~min}\right)$. The first round of PCR products $(5 \mu \mathrm{l})$ was diluted $(1: 20)$ and used as a template for a second PCR reaction using the PGK2A and PGK2B primers. The amplification procedure was the same as during the first round, except that the annealing temperature was $56^{\circ} \mathrm{C}$. The PCR products were digested with 5 Units $B s t \mathrm{XI}$ at $48^{\circ} \mathrm{C}$ for $8-10 \mathrm{~h}$ in a $20-\mu \mathrm{l}$ mixture containing $0.2 \mu \mathrm{l}$ of $10 \mathrm{~g} / \mathrm{l}$ BSA and $2 \mu \mathrm{l}$ of $10 \mathrm{X}$ reaction buffer. The digested products were resolved in $2 \%(\mathrm{~g} / \mathrm{Ml})$ agarose gel containing ethidium bromide $(0.2 \mathrm{mg} / \mathrm{l})$.

For the AR gene, two pairs of primers were used as previously described (12). The amplification efficiency was verified by resolving the PCR reaction aliquots on $2 \%$ agarose gels. The PCR products ( $4 \mu \mathrm{l}$ each) were mixed with the same volume of loading buffer $(1 \mathrm{~g} / 1$ xylene cyanole and $1 \mathrm{~g} / \mathrm{l}$ bromophenol blue in formamide) and resolved on an $8 \%$ polyacrylamide gel containing $8 \mathrm{~mol} / \mathrm{l}$ urea using the Mini-VE System (Amersham Biosciences, San Francisco, CA, USA) at $120 \mathrm{~V}$ for $4 \mathrm{~h}$. Bands were visualized using silver staining.

Analysis and assessment of PCR products for clonality assay. PCR gel images were photographed, and the intensities of the PCR bands for both alleles were quantitated using an imageanalyzing system (LabWorks 3.0, UVP, Cambridge, UK). A reduction in fluorescence intensity of $\geq 50 \%$ for both bands compared with the intensity of the bands obtained in the absence of $\mathrm{HpaII}$ or HhaI digestion was used as an indicator of the loss of X-chromosome inactivation mosaicism (13). A corrected ratio (CR) was calculated by dividing the ratio of the upper-band intensity by the lower-band intensity, or viceversa, of the same sample before and after digestion to give a $C R$ value $>1$. A CR value $\geq 2$ was used to define a loss of $\mathrm{X}$-chromosome inactivation mosaicism.

PCR amplification and mutation analysis of c-KIT. Exons 9, 11,13 and 17 of the c-KIT gene were evaluated for the presence of mutations by PCR amplification and sequencing. The primer pairs used for PCR amplification are listed in Table I. Briefly, the PCR reaction was carried out in a 50- $\mu$ l final volume with $4 \mu \mathrm{l}$ of $10 \mathrm{mM}$ dNTP (Gibco), the forward (F) and reverse (R) primers ( 0.4 pmol each), $5 \mu \mathrm{l}$ of 10X buffer, $1.5 \mu 1$ of $50 \mathrm{mM} \mathrm{MgCl}_{2}$, and 2.5 Units of Taq DNA polymerase (Gibco). Amplification was conducted using a PT-200 thermocycler (MJ Research Inc.) for 35 cycles $\left(95^{\circ} \mathrm{C}\right.$ for $30 \mathrm{sec}, 56^{\circ} \mathrm{C}$ or $60^{\circ} \mathrm{C}$ for $40 \mathrm{sec}$, and $72^{\circ} \mathrm{C}$ for $30 \mathrm{sec}$ ). PCR products were separated by $2 \%$ agarose ethidium bromide gel electrophoresis to confirm correct amplification, then ligated to the pGEM-T plasmid vector. The recombinant vector was transformed into E. coli DH5- $\alpha$ with the positive clone selected by blue/ white screening. Restriction enzyme digestion with EcoRI and $B a m \mathrm{HI}$ as well as gel electrophoresis analysis and sequencing of the digestion products were performed to identify the recombinant. The appropriate plasmid was sent to Shanghai Biotechnology Co. Ltd. for purification and sequencing.

\section{Results}

Pathological observations. The resected mass, including the greater omentum and tumors of unequal size, was $20 \times 16.5 \times 13 \mathrm{~cm}$ in size (Fig. 1). The specimen consisted of 15 irregular fragments of soft-tissue mass measuring from $10 \times 8.5 \times 7 \mathrm{~cm}$ (the largest) to $4.8 \times 3.5 \times 2 \mathrm{~cm}$ (the smallest). Most of the tumors had complete capsules, with a gray-yellow cut surface and focal hemorrhaging. Microscopically, the samples 
Table I. c-KIT gene oligonucleotide primers.

\begin{tabular}{|c|c|c|c|c|}
\hline c-KIT exon & & Sequence ( $\left.5^{\prime}-3^{\prime}\right)$ & Length of PCR product & $\begin{array}{l}\text { Annealing temperature } \\
\left({ }^{\circ} \mathrm{C}\right)\end{array}$ \\
\hline \multirow[t]{2}{*}{9} & $(\mathrm{~F})$ & 5'-TCC TAG AGT AAG CCA GGG CTT T-3' & 283 & 56 \\
\hline & $(\mathrm{R})$ & 5'-TGG TAG ACA GAG CCT AAA CAT CC-3' & & \\
\hline \multirow[t]{2}{*}{11} & $(\mathrm{~F})$ & 5'-CTG AGA CAA TAA TTA TTA AAA GGT GA-3' & 227 & 60 \\
\hline & $(\mathrm{R})$ & 5'-TTA TGT GTA CCC AAA AAG GTG ACA-3' & & \\
\hline \multirow[t]{2}{*}{13} & $(\mathrm{~F})$ & 5'-GCT TGA CAT CAG TTT GCC AG-3' & 193 & 60 \\
\hline & $(\mathrm{R})$ & 5'-AAA GGC AGC TTG GAC ACG GCT TTA-3' & & \\
\hline \multirow[t]{2}{*}{17} & $(\mathrm{~F})$ & 5'-TAC AAG TTA AAA TGA ATT TAA ATG GT-3' & 228 & 56 \\
\hline & $(\mathrm{R})$ & 5'-AAG TTG AAA CTA AAA ATC CTT TGC-3' & & \\
\hline
\end{tabular}

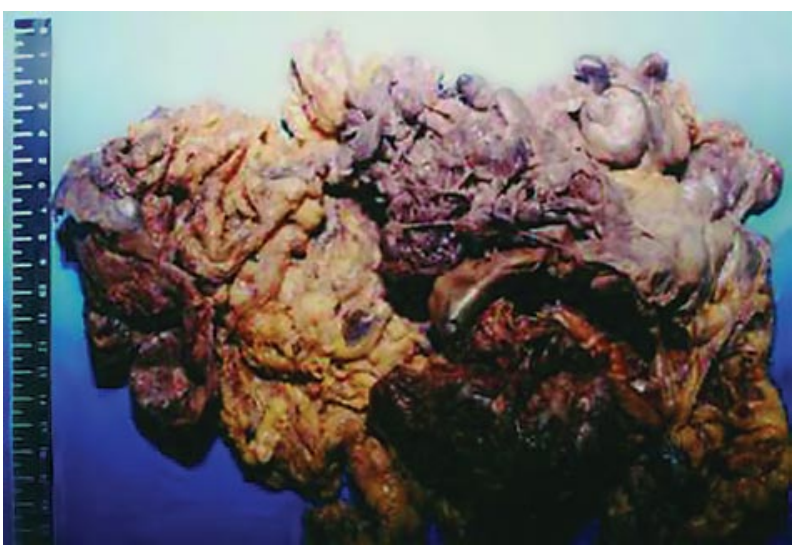

Figure 1. The resected mass, including the greater omentum and tumors of unequal size, was $20 \times 16.5 \times 13 \mathrm{~cm}$ in size.

shared typical histological characteristics. The lesions were composed of spindle cells arranged in cords, knitted and whirlpool patterns, with abundant cytoplasm. Staff or fusiform cells were observed in the nuclei, and mitosis was clearly visible. Immunohistochemistry reavealed the spindle cells to be positive for CD117 (Fig. 2A), CD34 (Fig. 2B) and vimentin, but not for desmin, S-100, SM-actin, NF, GFAP, NSE, HMB-45 or SC-actin.

Determination of clonality. The clonality assay revealed the presence of polymorphisms at the PGK and AR loci in all samples. In the PGK and AR PCR gel images, the DNA samples of the tissues without HpaII or HhaI digestion showed two bands. When the DNA samples of the lesion tissue were digested with HpaII or HhaI, the lower bands from all 15 different lesions disappeared (Fig. 3A and B). Thus, monoclonality was demonstrated for the lesions, suggesting that they were neoplastic. However, the intensities of the two bands were equal to that of the surrounding fibrous connective tissue with or without HpaII or HhaI digestion.

Amplification and detection of c-KIT gene mutations at exons 9, 11, 13 and 17. Amplification efficiency for exons 9, 11, 13
A

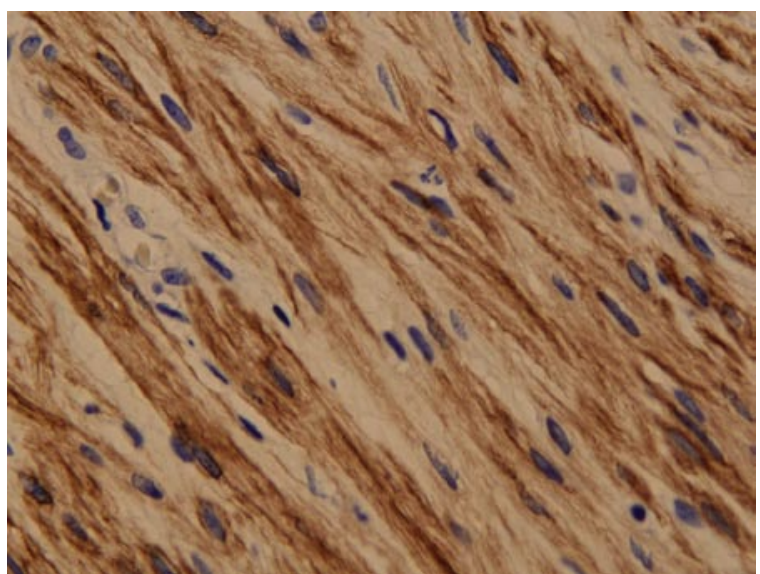

B

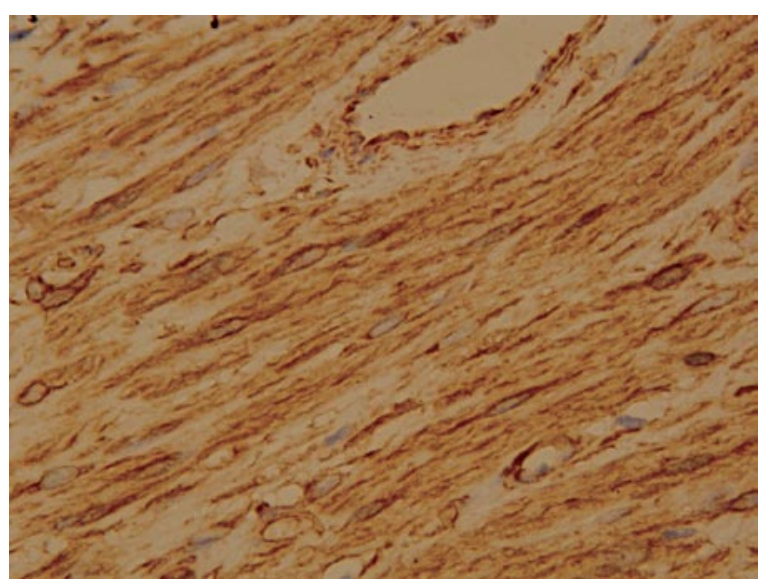

Figure 2. Immunohistochemistry showing tumor cells positive for CD117 (A) and CD34 (B).

and 17 of the c-KIT gene was verified by resolving PCR reaction aliquots on $2 \%$ agarose gels. The results showed that there were three bands (from 3 tumor nodules) for exon 9 at $283 \mathrm{bp}$, three bands (from 3 tumor nodules) for exon 11 at $227 \mathrm{bp}$, four bands (from 4 tumor nodules) for exon 13 at $193 \mathrm{bp}$ and three bands (from 3 tumor nodules) for exon 17 at 228 bp (Fig. 4). This confirmed the diagnosis of GIST. Mutations of the c-KIT 
A
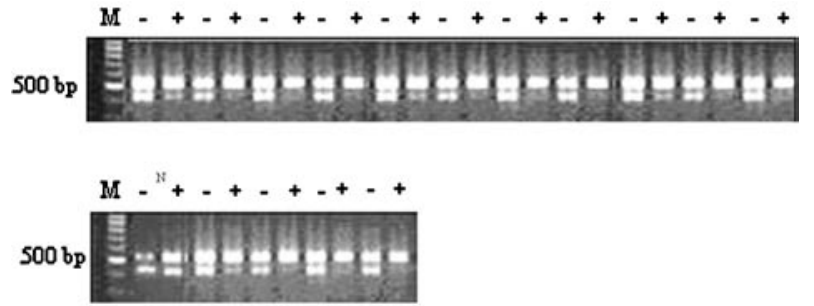

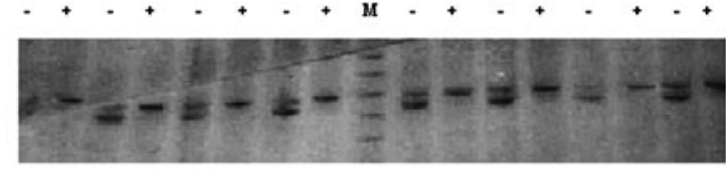

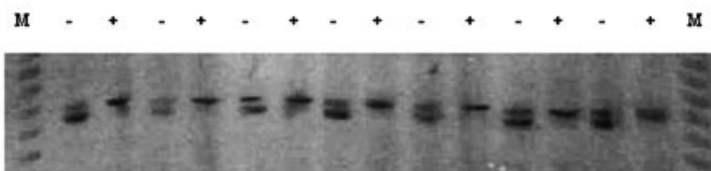

Figure 3. (A) DNA samples of the lesion tissue digested with HpaII. The lower bands of the 15 tumor nodules exhibited markedly reduced intensity or the disappearance of the PGK gene loci. (B) DNA samples of the lesion tissue digested with HhaI. The lower bands of 15 tumor nodules exhibited markedly reduced intensity or the disappearance of the AR gene loci. -, pretreated without HpaII; +, pretreated with HpaII; M, DNA marker; N, fibrous connective tissue.

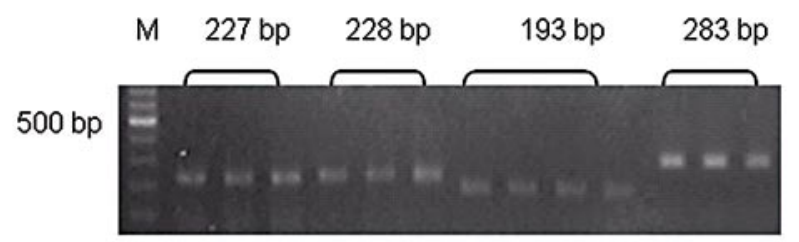

Figure 4. The results of $2 \%$ agarose gel electrophoresis. Visible are three bands (from 3 tumor nodules) for exon 9 at 283 bp, three bands (from 3 tumor nodules) for exon 11 at $227 \mathrm{bp}$, four bands (from 4 tumor nodules) for exon 13 at $193 \mathrm{bp}$, and three bands (from 3 tumor nodules) for exon 17 at $228 \mathrm{bp}$.

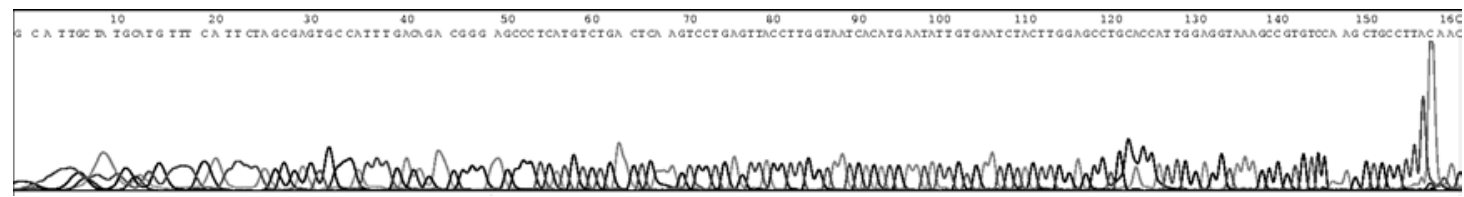

Figure 5. Results of sequencing for exon 13. The deletion of base pairs was observed at multiple locations, including $31 \mathrm{bp}$ (C), $42 \mathrm{bp}$ (A), $57 \mathrm{bp}$ (A) and $61 \mathrm{bp}(\mathrm{A})$.

gene at exons 9, 11, 13 and 17 were additionally examined according to PCR methods and molecular clones. The result of sequencing for exon 13 was GCA T TGC TAT GCA TGT TTC ATT TA GCG AGT GCC AT TTG ACA GA CGG GA GCC CTC ATG TCT GA CTC AA GTC CTG AGT TAC CTT GGT AAT CAC ATG AAT ATT GTG AAT CTA CTT GGA GCC TGC ACC ATT GGA GGT AAA GCC GTG TCC AAG CTG CCT T ACAACCTA. Compared with the genomic sequence of c-KIT (CGA GTG CCC ATT TGA CAG AAC GGG AAG CCC TCA TGT CTG AAC TCA AAG TCC TGA GTT ACC TTG GTA ATC ACA TGA ATA TTG TGA ATC TAC TTG GAG CCT GCA CCA TTG GAG G) the exon 13 sequence indicated the deletion of base pairs at multiple locations, including 31 (C), 42 (A), 57 (A) and 61 bp (A) (Fig. 5), but not in the following domain (exons 9,11 and 17).

\section{Discussion}

EGISTs are histologically and immunohistochemically similar to their gastrointestinal counterparts, but have an aggressive course resembling small intestinal stromal tumors, and little or no connection to the abdominal wall or the serosal surface of the gastrointestinal tract (6). The cells of origin of EGISTs are unknown. Agaimy and Wunsch reviewed 200 cases of GISTs and observed some degree of association with the muscularis propria of the gut wall, concluding that most socalled EGISTs are actually apparent EGISTs that initally arose from the outermost muscle coat, but lost contact with the point of origin due to an extensive extramural growth pattern (14). Moreover, they suggested that the incidence of pure EGISTs is just 5-10\%. Thus, documenting and marking any focal attachments or adhesions to the gut wall observed during surgery is essential.

In the present case, multiple round and well-defined softtissue masses with homogenous and heterogeneous patterns in the uterus and spleen, between the uterus and bladder, in the right lobe of the liver and in the parietal peritoneum were found during surgery, but were probably not appended to the gut wall.

The presence of CD117 (the c-KIT protooncogene protein product) in EGISTs has been immunohistochemically demonstrated (15). CD117 is a transmembrane receptor for the growth factor known as stem cell factor. It is expressed in hematopoietic stem cells, mast cells, germ cells and melanocytes (16), and is believed to play a key role in the development and maintenance of these cell populations. Furthermore, CD117 is present in a neural-related population of gastrointestinal mesenchymal cells, 
which are the interstitial cells of Cajal in the muscular layers. These cells are functionally important for gastrointestinal motility, and show pacemaker activity $(15,17)$. It was also reported that $90-95 \%$ of GISTs express CD117, 60-70\% CD34, 30-40\% SM-actin, and only 5\% S-100 protein. GISTs are, of course, always positive for vimentin, and can be differentiated from other mesenchymal tumors, such as schwannomas or leiomyomas, according to their immunohistochemical characteristics.

In the present study, the results demonstrated that the tumor cells were positive for $\mathrm{CD} 117, \mathrm{CD} 34$ and vimentin, but negative for CK, EMA, MC, CR, NSE, S-100, HMB45, Melanoma-pan, NF, GFAP, desmin, SM-actin, among others. Consequently, other mesenchymal tumors, such as schwannomas, leiomyomas and mesotheliosarcoma, could be excluded.

Several studies have revealed various types of c-KIT oncogene mutations, including exon 11 encoding the juxtamembrane domain, exon 9 encoding the extracellular domain and exons 13 and 17 encoding the tyrosine kinase domain (1). In this study, exons 9, 11, 13 and 17 of the c-KIT gene were evaluated for the presence of mutations by PCR amplification and sequencing in order to confirm the diagnosis of GIST and to elucidate the observed c-KIT gene mutations. The results demonstrated that PCR amplification was successful for exons 9, 11, 13 and 17. The c-KIT gene mutation was found in exon 13 .

Monoclonality is one of the main features of most tumors, whereas normal and reactive hyperplastic lesions are polyclonal (18). The clonality assay is based on X-chromosome inactivation mosaicism and polymorphisms at the PGK and AR loci in female somatic cells. There are two X-chromosomes within each female somatic cell. One of these is randomly inactivated by methylation during early embryogenesis, while the other preserves its genetic activity throughout life. In the PGK gene, the presence of an SNP downstream from the methylation site was identified by BstXI (19), while a polymorphism showing different lengths of the CAG short-tandem repeat was identified at exon 1 of the AR gene (20). After digestion with the methylation-sensitive restriction enzymes HpaII or HhaI, normal and reactive hyperplastic tissues containing polymorphisms showed two alleles of equal intensity. Neoplastic tissues showed only one or one of two alleles with markedly reduced intensity (21).

In recent years, GISTs have been considered mesenchymal tumors. Only a few reports have investigated their clonal origin $(10,11)$. Most GISTs are monoclonal hyperplasia; however, a few of the tumors are polyclonal. This raises the questions: are EGISTs or multiple EGISTs monoclonal? What is the relationship between the different tumor nodules in multiple EGISTs? The results of the present study demonstrated the investigated EGIST to be monoclonal, similar to the results of Chen et al (11). Fifteen different tumor nodules showed a loss of identical $\mathrm{X}$-chromosome inactivation mosiacism, indicating that they had a common clonal origin. It was unclear whether these multiple tumors were caused by the extensive invasion of tumors from a single cell, or whether they had multicentric origins. Cai et al analyzed 55 cases of multiple leiomyomas for their X-chromosome inactivation patterns, and revealed random inactivation patterns among different tumor nodules in $20(36 \%)$ of the cases, indicating that they were of independent multicentric origins (22). However, in 29 cases (53\%), an identical inactivated allele was found in all tumor nodules from the same uterus. In addition, seven nodules from a multinodular case with a morphology indicative of mitotically active leiomyoma were shown to carry the identical inactivated allele, demonstrating their unicellular origin and malignant nature. Thus, Cai et al concluded that the relationship between different tumor nodules from multiple uterine leiomyomas was not simple, and could be subtyped into fully independent and aggressive types, as well as a mixed type. In the present study, we deduced that multiple EGISTs could be caused by the extensive invasion of tumors. However, more cases must be analyzed to determine whether all multiple EGISTs exhibit similar characteristics.

\section{Acknowledgements}

This study was supported by the National Natural Science Foundation of China (no. 30800417) and the National Basic Research Program (973 Program) of China (no. 2009CB521705).

\section{References}

1. Kinoshita K, Hirota S, Isozaki K, Ohashi A, Nishida T, Kitamura Y, Shinomura Y and Matsuzawa Y: Absence of c-KIT gene mutations in gastrointestinal stromal tumours from neurofibromatosis type 1 patients. J Pathol 202: 80-85, 2004.

2. Miettinen M, Monihan JM, Sarlomo-Rikala M, Kovatich AJ, Carr NJ, Emory TS and Sobin LH: Gastrointestinal stromal tumors/smooth muscle tumors (GISTs) primary in the omentum and mesentery: clinicopathologic and immunohistochemical study of 26 cases. Am J Surg Pathol 23: 1109-1118, 1999.

3. Joensuu H, Fletcher C, Dimitrijevic S, Silberman S, Roberts P and Demetri G: Management of malignant gastrointestinal stromal tumours. Lancet Oncol 3: 655-664, 2002.

4. Fletcher CD, Berman JJ, Corless C, Gorstein F, Lasota J, Longley BJ, Miettinen M, O'Leary TJ, Remotti H and Rubin BP: Diagnosis of gastrointestinal stromal tumors: a consensus approach. Hum Pathol 33: 459-465, 2002.

5. Lewis JJ, Leung D, Woodruff JM and Brennan MF: Retroperitoneal soft-tissue sarcoma: analysis of 500 patients treated and followed at a single institution. Ann Surg 228: 355-365, 1998.

6. Reith JD, Goldblum JR, Lyles RH and Weiss SW: Extragastrointestinal (soft tissue) stromal tumors: an analysis of 48 cases with emphasis on histologic predictors of outcome. Mod Pathol 13: 577-585, 2000.

7. Urbanczyk K, Limon J, Korobowicz E, Chosia M, Sygut J, Karcz D, Iwanik K, Osuch C, Lasota J and Stachura J: Gastrointestinal stromal tumors. A multicenter experience. Pol J Pathol 56: 51-61, 2005.

8. Cypriano MS, Jenkins JJ, Pappo AS, Rao BN and Daw NC: Pediatric gastrointestinal stromal tumors and leiomyosarcoma. Cancer 101: 39-50, 2004.

9. Miettinen M and Lasota J: Gastrointestinal stromal tumors: review on morphology, molecular pathology, prognosis and differential diagnosis. Arch Pathol Lab Med 130: 1466-1478, 2006.

10. Haller F, Schulten HJ, Armbrust T, Langer C, Gunawan B and Fuzesi L: Multicentric sporadia gastrointestinal stromal tumors (GISTs) of the stomach with distinct clonal origin: differential diagnosis to familial and syndromal GIST variants and peritoneal metastasis. Am J Surg Pathol 31: 933-937, 2007.

11. Chen H, Hirota S, Isozaki K, Sun H, Ohashi A, Kinoshita K, O'Brien P, Kapusta L, Dardick I, Obayashi T, Okazaki T, Shinomura Y, Matsuzawa Y and Kitmura Y: Polyclonal nature of diffuse proliferation of interstitial cells of Cajal in patients with familial and mutiple gastrointestinal stromal tumours. Gut 51: 793-796, 2002.

12. Gong L, Zhang W and Su Q: Clonal status of fibrous dysplasia. Pathology 40: 392-395, 2008.

13. Wang SF, Su Q, Zhu SJ and Liu J: Clonality of multiple uterine leiomyomas. Zhonghua Bing Li Xue Za Zhi 31: 107-111, 2002.

14. Agaimy A and Wunsch PH: Gastrointestinal stromal tumours: a regular origin in the muscularis propria, but an extremely diverse gross presentation: A review of 200 cases to critically re-evaluate the concept of so-called extra-gastrointestinal stromal tumours. Langenbecks Arch Surg 391: 322-329, 2006. 
15. Corless CL, McGreevey L, Haley A, Town A and Heinrich MC: KIT mutations are common in incidental gastrointestinal stromal tumors one centimeter or less in size. Am J Pathol 160: 1567-1572, 2002.

16. Miettinen M, Sobin LH and Sarlomo-Rikala M: Immunohistochemical spectrum of GISTs at different sites and their differential diagnosis with a reference to CD117 (KIT). Mod Pathol 13: 1134-1142, 2000

17. Yamamoto H, Oda Y, Kawaguchi K, Nakamura N, Takahira T, Tamiya S, Saito T, Oshiro Y, Ohta M, Yao T and Tsuneyoshi M: c-KIT and PDGFRA mutations in extragastrointestinal stromal tumor (gastrointestinal stromal tumor of the soft tissue). Am J Surg Pathol 28: 479-488, 2004.

18. Su Q: Precancerous lesions of human hepatocellular carcinoma. Zhen Duan Bing Li Xue Za Zhi 10: 112-115, 2003.
19. Vogelstein B and Fearon ER: Use of restriction fragment length polymorphism to determine the clonal origin of human tumors. Science 227: 642-644, 1985

20. Allen RC, Zoghbi HY and Moseley AB: Methylation of HpaII and HhaI sites near the polymorphic CAG repeat in the human androgen-receptor gene correlates with $\mathrm{X}$ chromosome inactivation. Am J Hum Genet 51: 1229-1239, 1992.

21. Su Q, Liu Q and Wang SF: Clonality analysis technology based on $\mathrm{X}$ chromosome genetic polymorphism and application. Zhonghua Bing Li Xue Za Zhi 31: 162-164, 2002.

22. Cai YR, Diao XL, Wang SF, Zhang W, Zhang HT and Su Q: $\mathrm{X}$-chromosomal inactivation analysis of uterine leiomyomas reveals a common clonal origin of different tumor nodules in some multiple leiomyomas. Int J Oncol 31: 1379-389, 2007. 